\title{
Building superlatives from property concept expressions
}

\author{
Mythili Menon*
}

\begin{abstract}
Although the relative versus absolute ambiguity in superlatives is well established, there is no consensus regarding how the comparison classes which gives rise to these ambiguities are determined. Two factors, the LF syntax of - est and fo-cus, have been said to determine the comparison classes. In this paper, I provide novel data from Malayalam, a language without adjectives, which require both a movement theory of superlatives and focus to derive the readings.
\end{abstract} Keywords. superlatives; property concept expressions; Dravidian

1. Introduction. Adjectival superlatives in English are ambiguous between two kinds of interpretation- Absolute interpretation and Relative interpretation (Ross 1964, Heim 1985, Szabolsci 1986 a.o). In (1a), the absolute reading arises as a result of different chocolates being compared to one another. The relative reading, however, depends on context. Suppose there are three chocolates in a shop called 'Cocoa Dolce' with the following price ranges, $\{x=\$ 2.99, y=\$ 3.99, z=$ $\$ 4.99$ \}. Imagine, both Mia and Eva bought chocolates for Anika. Eva bought $x$ and Mia bought $y$, but no one bought $z$. In this context, there is intonational prominence on 'Mia' and a relative interpretation holds (1b). In this situation, 'Mia' is being compared with every other person who bought a chocolate for Anika. The relative interpretation is sensitive to focus, often marked with prosodic prominence in English. Changing the prosodic prominence in the sentence changes the relative reading available. Thus, shifting focus to Anika, results in a different relative reading (1c), where the comparison class is constituted by the recipients of the chocolates.

(1) Mia bought the most expensive chocolate for Anika.

a. Absolute reading: Mia bought Anika the chocolate that was more expensive than any other chocolate.

b. Relative reading: Mia bought Anika a more expensive chocolate than anyone else bought her.

c. Relative reading: Mia bought Anika a more expensive chocolate than she bought for anyone else.

The ambiguity modeled in the absolute reading is related to the comparison class, determined on the basis of the DP containing the superlative expression (e.g. 'the most expensive chocolate'). Thus, in the absolute reading in (1a), the comparison class is the contextually salient set of chocolates. As seen in $(1 \mathrm{~b}, 1 \mathrm{c})$, focus is needed to disambiguate the two relative readings, yet it does not exclude the availability of the absolute reading (1a). Determining how the relative readings come about is a topic still under debate. Two main theories have been proposed- the role of the superlative marker - est, and the role of focus. The role of the superlative marker depends on the relative position of the -est marker to the DP at LF. Two main versions of this theory exist- The movement theory and the DP-internal theory. Under the movement theory, relative readings arise when the - est marker moves out of the superlative DP to a scope position

\footnotetext{
* Many thanks to Roumyana Pancheva, Rajesh Bhatt, and the audience of the 2017 Linguistic Society of America's Annual Meeting at Austin, TX for valuable comments and suggestions. Any errors are my own. Author: Mythili Menon, Wichita State University (mythili.menon@wichita.edu).
} 
in the clause (Heim 1985, 1999, Szabolsci 1986). Under the DP-internal theory, the - est marker stays and scopes inside the DP in both absolute and relative readings (Farkas and Kiss 2000, Sharvit and Stateva 2002). Both theories do not require focus to derive the relative readings. Evidence for lack of focus for the derivation of relative readings comes from examples such as (2), where prosodically non-prominent elements who or its trace can determine comparison class (Szabolsci 1986, Heim 1999).

(2) We should congratulate the boy who got the most expensive $[\mathrm{CAKE}]_{\mathrm{F}}$

Under the movement theory, the superlative marker - est is a quantifier over degrees and therefore can take different scope within the clause. When - est scopes inside the superlative DP, the interpretation is absolute. When - est takes external scope, the relative interpretations obtain, with the superlative DP considered as an indefinite DP at LF. The semantics of -est is given in (3), from Heim (1999).

$$
\begin{aligned}
& \llbracket \text {-est } \rrbracket=\lambda C_{\langle\mathrm{e}, \mathrm{t}\rangle} \cdot \lambda D_{\langle\mathrm{d}, \mathrm{et}\rangle} \cdot \lambda x_{\mathrm{e}} \cdot \exists d[D(d)(x) \wedge \forall y \in C[y \neq x \rightarrow \neg(D(d)(y))]] \\
& \text { Presuppositions: } x \in C, \forall y[y \in C \rightarrow \exists d[D(d)(y)]] .
\end{aligned}
$$

The - est marker is a degree quantifier with three arguments. The first argument takes a set of individuals, $C$. This is the covert restrictor of the superlative marker specifying the comparison class. The second argument is a gradable predicate, $D$, and the third argument is an individual $x$. The LF syntax of [-est $C$ ] creates an abstract over degrees and through the second part of the presupposition, all members of the comparison class $\mathrm{C}$ have the property specified by the sister node of [-est C]. On the movement theory, the relative readings are determined by scope ambiguities. Thus, under the movement theory, the different readings of the adjectival superlative DP results from different comparison classes $C$, derived through scope. In the DPinternal theory, the relative readings are derived on the basis of context dependency from a single LF.

Although we understand a great deal about how superlatives are derived in languages with adjectives, very little is known about how superlatives are formed in a language without a lexical category of adjectives, and the availability versus non-availability of absolute/relative ambiguity. In the rest of the paper, novel evidence from superlatives formed from property concept expressions in Malayalam will point to the need of a focus-based theory, combined with the movement theory, to account for superlative expressions build from property concept expressions, in the absence of both adjectives and an overt - est marker in the language.

2. Previous Account of Malayalam Property Concept Expressions. In previous work, I have shown that Malayalam lacks an adjectival category and uses syntactically complex expressions for predication, attributive modification, and comparison (Menon 2013, Menon and Pancheva 2014). Structurally complex 'adjective-like' expressions are built on the basis of property- concept denoting roots, i.e., roots with meanings such as height, beauty, intelligence (Chierchia and Turner 1988, Koontz-Garboden and Francez 2010, Francez and Koontz- Garboden 2017). Lexemes formed on the basis of such roots belong to two classes which differ in their syntactic category, and correspondingly, exhibit different syntactic behavior when they build bigger structures used for predication, attribution, and comparison. Some examples of Class 1 and Class 2 property concept expressions are given in (4) and (5). Class 1 expressions are $-a$-ending reduced (participial) relatives ( $-a$ being the Proto-Dravidian relative marker) and Class 2 expressions are am-ending nominals (-am being a nominal marker). Class 1 expressions are formed on the basis 
of native roots whereas Class 2 roots are borrowed from Sanskrit.

$$
\begin{aligned}
& \text { valiya 'big', čeriya 'small', puthiya 'new', pazhaya 'old', nalla 'good' } \\
& \text { santosham 'happiness', sankatam 'sadness', prayasam 'difficulty' }
\end{aligned}
$$

In Menon and Pancheva (2014), we suggested that both Class 1 and Class 2 property concept expressions start out as roots denoting abstract mass substances (notated by $\Pi$ ), which, following Chierchia and Turner (1988), have the type of entities.
a. $\left[V_{\text {nalla }}\right]=$ the property of goodness
(Class 1)
b. $[\sqrt{ }$ santosham $]=$ the property of happiness (Class 2$)$

The core idea is that these roots are turned into predicates of individuals through possessive predication, and to have $\Pi$ means to have an instance, a certain amount, of $\Pi$, i.e., possessive predicates formed on the basis of property-concept roots are gradable.

2.1 CLASS 1 PROPERTY CONCEPT EXPRESSIONS. Class 1 roots are verbalized first, with a null possessive $v$, before the addition of the relative marker $-a$. Support for the presence of the null verbal head comes from the distribution of the relative marker $-a$ : $-a$ only merges with verbs. Hence, Class 1 roots are turned into nonfinite verbal expressions by the addition of a null $v$, which, as we suggested in Menon and Pancheva (2014), has possessive semantics, as in (7).

$$
\llbracket \varnothing_{\mathrm{V} \_ \text {poss } \rrbracket}=\lambda \Pi . \lambda d . \lambda x . \exists y[y \text { is an instance of } \Pi \text { and } x \text { has } y \text { and } \mu(y) \geq d]
$$

The degree argument is bound by the non-overt positive morpheme POS. The meaning of forms such as those in (8) is norm-related - they are interpreted as making reference to a standard, as would be expected if $P O S$ is binding the degree variable word-internally.

$$
\begin{aligned}
& \llbracket \text { nalla } \rrbracket=\lambda x . \exists d \exists y\left[y \text { is an instance of goodness } \& x \text { has } y \& \mu(y) \geq d \& d>d_{S}\right] \approx \lambda \mathrm{x} . \\
& \exists \mathrm{d}\left[\mathrm{x} \text { 's goodness } \geq \mathrm{d} \text { and } \mathrm{d}>\mathrm{d}_{\mathrm{s}}\right]
\end{aligned}
$$

Class 1 forms are gradable and they can attributively modify nominals and appear in the predicative position after being nominalized, the same form used to form comparatives. Moreover, Class 1 forms never allow the comparative marker kuututtal 'more'.
a. nalla kutti
good child
'Good child'
b. kutti nalla-van aano
child good-NOML EQ-COP
'The child is good'
c. Anil Komalan-e kaalum (*kuututtal) nalla-van aanə
Anil Komalan-ACC than more good-NOML EQ-COP
'Anil is more good than Komalan.'

2.2. ClASS 2 PROPERTY CONCEPT EXPRESSIONS. Class 2 property concept roots end in -am, a Proto-Dravidian nominal marker. The Class 2 property concept roots first compose with the null $v$ 
head without possessive semantics. The nominal marker - am then nominalizes this expression. The null $v$ head does not incorporate a degree argument, unlike Class 1 property concept expressions. The existential copula, untə, then turns the nominal into a gradable predicate.

a. $\left[\left[\left[\vee_{\mathrm{pokk}}+\varnothing_{\mathrm{V}}\right]+a m_{\mathrm{n}}\right] \mathrm{n}\right.$

b. $\llbracket \varnothing_{\mathrm{V}} \rrbracket=\lambda \Pi$. $\lambda x[x$ is an instance of $\Pi]$

c. 【pokkam $\rrbracket=\lambda x$. [x is an instance of tallness $]$

Class 2 expressions are not gradable. They are made gradable optionally overtly using the comparative marker or a measure phrase. An existential degree quantifier, without norm-related semantics (unlike the case of Class 1 forms, where POS binds the degree argument), binds the degree argument introduced with possessive predication.

Although these expressions can appear as such in the predicative position along with the existential copula, they have to be overtly relativized, using the non-finite existential copula 'ull' and the relative marker $-a$, for attributive modification. In the comparative form, they can optionally appear with the comparative marker kuututtal 'more'.
a. pokkam ulla kutti
tallness having child
'a tall child'
b. kutti-kkə pokkam untə
child-DAT tallness EX-COP
'The child is tall.'
c. Anil-ino Komalan-e kaalum (kuututtal) pokkam unto
Anil-DAT Komalan-ACC than more tallness EX-COP
'Anil is taller than Komalan.'

Thus, Class 1 and Class 2 property concept roots exhibit different syntactic and semantic behavior in attributive, predicative, and comparative constructions, based on the functional categories they initially merge with ${ }^{1}$. In the next section, I discuss how superlatives are formed using these property concept expressions.

3. Malayalam Superlatives. In the absence of adjectives, superlatives are built over Class 1 and Class 2 property concept expressions. Unlike English, Malayalam does not have an inflectional est marker, a periphrastic marker meaning 'most' is used. ettavum 'most' is an intensifier', derived from the quantifier 'eere', meaning 'a lot'. The superlatives are derived from the attributive forms of the Class 1 and Class 2 property concept expressions by means of the intensifier. These attributive forms are relativized, using the $-a$ marker, as discussed in Section 2 . The attributive, relativized property concept expression first combines with the noun and the superlative combines with this nominal complex, as shown in (12).
a. ettavum nalla kutti
most good child

(Class 1)

'The best child.'

\footnotetext{
${ }^{1}$ For more details about the formation of these structures, see Menon (2016).

${ }^{2}$ The $-u m$ marker is characteristic of strong quantifiers. See Jayaseelan (2011) for a discussion.
} 


$$
\begin{array}{lll}
\text { b. ettavum } & \text { pokkam } & \text { ulla kutti } \\
\text { most } & \text { tall } & \text { having child }
\end{array}
$$

'The tallest child.'

Note that in the absence of a definite article, the bare DPs in (12) are ambiguous between a definite and an indefinite reading. The predicative form of the superlative, after nominalization, can also combine with the intensifier, as shown below.
a. kutti
child
most
ettavum
nalla-van
aano
'The child is the best.'
b. kutti ettavum
child most
good-NOML EQ-COP
'The child is the one having the most tallness.'

$\begin{array}{lll}\text { pokkam } & \text { ulla-van } & \text { aano } \\ \text { tallness } & \text { having-NOML } & \text { EQ-COP }\end{array}$

Note that both Class 1 and Class 2, superlatives are formed over the relativized property concept expressions, not on the comparative form of the property concept expression, as shown below. Though note that (14b) can be used with Class 2 comparative property concept expressions, in constructions that require extra emphasis. Thus, the comparative marker 'more' is optional in the formation of superlatives with property concept expressions, unlike the requirement for adjectival superlatives which are built on top of the comparative form of the adjective (see Bobaljik 2012).
a. kuututtal pokkam ulla
more tall having
'taller'
b. ettavum kuututtal pokkam ulla
most more tallness having
'The tallest'

To summarize, superlatives are formed on relativized property concept expressions. Both Class 1 and Class 2 property concept expressions can appear in the attributive and predicative forms in the superlative DP. The superlative is not built over the comparative form of the property concept expressions, though building the superlative over the comparative of Class 2 expressions can lead to extra emphasis. Class 1 expressions disallow the comparative marker, and hence, the superlative of Class 1 is always built over the relativized form.

Recall that English adjectival superlatives are ambiguous between the absolute and relative readings. The primary observation about Class 1 and Class 2 property concept superlatives is that unlike their English counterparts, these superlatives do not express an ambiguity between absolute and relative readings. Consider (15) below, with a Class 1 superlative.

$\begin{array}{llll}\text { Anil Komalan-ə ettavum } & \text { waliya cake } & \text { vaayni kotuttu } \\ \text { Anil } & \text { Komalan-DAT most } & \text { big cake bought give }\end{array}$

'Anil bought Komalan the biggest cake.' (Only Absolute reading)

The only reading available, with neutral intonation, in (15) is that Anil bought Komalan the cake that was bigger than any other cake. This is expected under the analysis of Class 1 
property concept expressions, such as waliya 'big', as explicated in Section 2.1. Also note that the superlative DP [ettavum waliya cake] is in the immediate preverbal position. Both the relative readings are absent. How are the relative readings derived? These readings come about through scrambling and association with focus.

3.1. Deriving Relative Readings. It has been well established, in Malayalam, that focus is marked using a dedicated FocP immediately to the left of the VP in the lower left periphery (Jayaseelan 2001, 2008). The element hosted in the FocP determines whether a relative reading is available or not. The spine of the lower left periphery is given in (16) below:

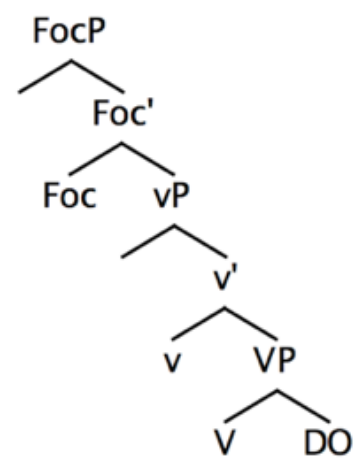

In the case of (15), the superlative DP [ettavum waliya cake] resides in the Foc position. Thus, the periphrastic - est marker 'ettavum' takes DP-internal scope and derives the absolute reading.

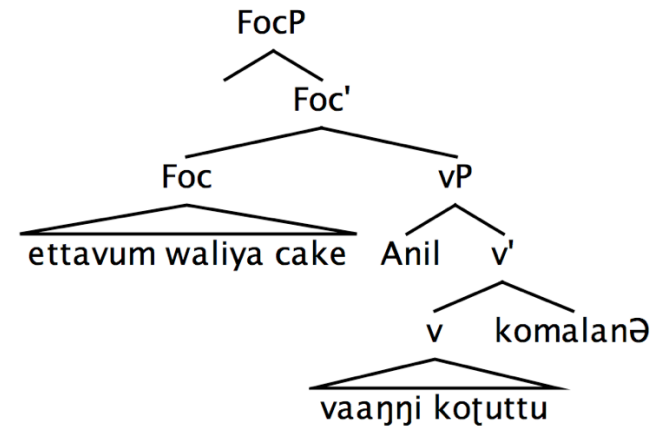

The subject 'Anil' moves to Spec TP for case licensing followed by remnant VP movement that fronts the object. The two relative readings are derived by scrambling the subject 'Anil' or the object 'Komalan' to the FocP position, as shown in (18). 
(18)

a. Komalanə ettavum waliya cake [Anil $]_{\mathrm{F}}$ vaayni kotuttu Komalan-dat most big cake Anil buy give

$\checkmark$ 'ANIL bought a larger cake for Komalan than anyone else did.'

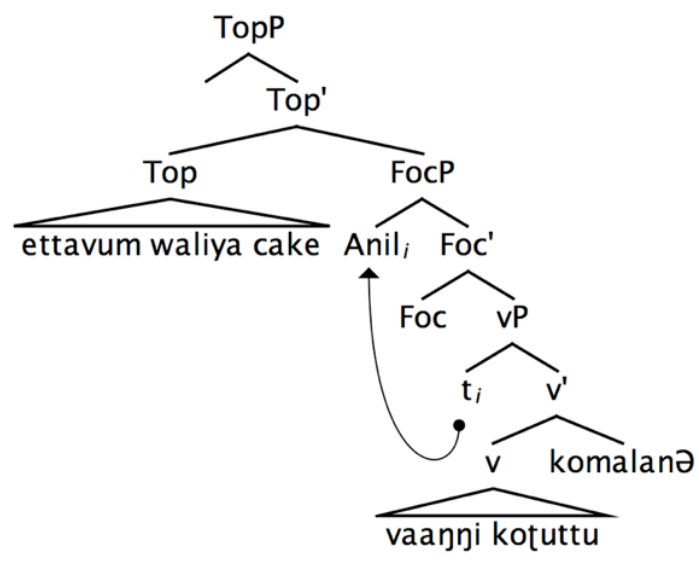

Here, the superlative DP is in a Topic position, above the FocP. Anil moves from the VPsubject internal position to the Spec of FocP. In the second relative reading, the prosodic prominence is on the object 'Komalan' which now sits in the FocP and derives the reading.

(20) Anil ettavum waliya cake [Komalanə] $]_{\mathrm{F}}$ vaanyi kotuttu

Anil most big cake Komalan-dat buy give

$\sqrt{ }$ 'Anil bought a larger cake for KOMALAN than he did for anyone else.'

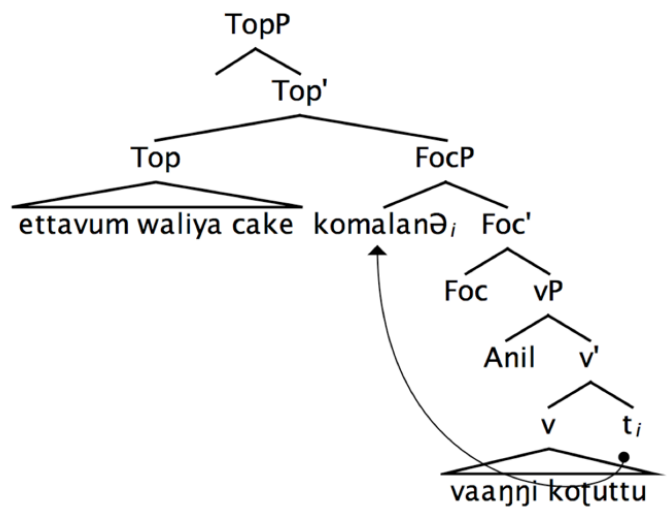


As seen, movement theory alone is not sufficient enough to derive the different readings. Moreover, the absolute reading is also dependent on focus and requires the superlative DP to be in the FocP position for the reading to hold. Thus, in a language without adjectives, focus is a necessary condition for deriving the absolute/relative ambiguity ${ }^{3}$.

4. Consequences and Conclusion. Malayalam, a language without adjectives, builds superlatives using relativized property concept expressions. The comparative form does not play a role, unless needed for extra emphasis. In the absence of true adjectival superlatives, the absolute/relative distinction disappears. In the language, the different readings can be derived by resorting to a focus position to the left of the VP. When the superlative DP resides in the FocP, absolute reading is derived. When either the subject or the object resides in the FocP, the relative reading is derived. Thus, focus is crucial to determining superlative ambiguities in the absence of true adjectival superlatives.

Recall that DPs in superlatives are ambiguous between a definite and indefinite reading, due to the lack of a definite article. A consequence of the analysis is that movement into the FocP renders the DP definite (also see Pancheva and Tomaszewicz 2012 for a DP-internal relative reading in the absence of the definite determiner in Polish).
a. ayaal [ettavum waliya cake] vaayniccu
he most big cake bought
'He bought the biggest cake.'
b. ettavum waliya cake [ayaal $]_{+ \text {def }}$ vaanjiccu most big cake he bought
'He bought the biggest cake.'

Languages without adjectives, such as Malayalam throw light on the two theories of forming superlatives- The role of the superlative marker -est and The focus theory. In these languages, both movement and focus is required to derive relative readings. Superlatives are ambiguous between a definite and an indefinite reading. Movement into a FocP disambiguates definiteness and the absolute/relative interpretation.

\section{References}

Bobaljik, Jonathan. 2012. Universals in Comparative Morphology: Suppletion, Superlatives, and the Structure of Words. MIT Press, Cambridge, MA.

Chierchia, Gennaro. \& Ray Turner 1988. Semantics and Property Theory. Linguistics and Philosophy 11, 261 - 302.

Farkas, Donka and Katalin É. Kiss. 2000. On the comparative and absolute readings of superlatives. Natural Language and Linguistic Theory 18, 417-455.

http://dx.doi.org/10.1023/a:1006431429816.

Francez, Itamar and Andrew Koontz-Garboden. 2017. Semantics and Morphosyntactic Variation. Oxford Studies in Theoretical Linguistics. Oxford: Oxford University Press.

Heim, Irene. 1985. Notes on comparatives and related matters. University of Texas, Austin: MS.

\footnotetext{
${ }^{3}$ I have omitted the exact semantics of the periphrastic 'most' which will play a role in deriving the readings using association of focus. I leave this for future work.
} 
Heim, Irene. 1999. Notes on superlatives. MIT, Cambridge: MS.

Jayaseelan, K. A. 2001. IP-internal Topic and Focus Phrases, Studia Linguistica 55, 39-75.

Jayaseelan, K.A. 2008. Topic, Focus, and Adverb Positions in Clause Structure. Nanzan Linguistics 4, 43-68.

Jayaseelan, K.A. 2011. Comparative morphology of quantifiers. Lingua 121: 269-286.

Koontz-Garboden, Andrew and Itamar Francez. 2010. Possessed Properties in Ulwa. Natural Language Semantics. 18 (2), pp. 197-240.

Menon, Mythili. 2013. The apparent lack of adjectival category in Malayalam and other related languages. In N. Goto, K. Otaki, A. Sato, K. Takita (eds.). Proceedings of GLOW-in-Asia IX 2012, 157-171.

Menon, Mythili. 2016. Building Adjectival Meaning without Adjectives. PhD Dissertation, University of Southern California.

Menon, Mythili, and Roumyana Pancheva. 2014. The grammatical life of property concepts in Malayalam. In, Proceedings of Sinn und Bedeutung 2013, University of Victoria-Gasteiz, Spain. pp. 289-302.

Pancheva, Roumyana and Barbara M. Tomaszewicz, 2012. Cross-linguistic differences in superlative movement out of nominal phrases. In Nathan Arnett and Ryan Bennett (eds.), West Coast Conference on Formal Linguistics (WCCFL) 30, 292-302. Somerville, MA: Cascadilla Proceedings.

Ross, John Robert. 1964. A partial grammar of English superlatives. University of Pennsylvania: MA Thesis.

Sharvit, Yael and Penka Stateva. 2002. Superlative expressions, context, and focus, Linguistics and Philosophy 25, 453-504. http://dx.doi.org/10.1023/a:1020875809794.

Szabolcsi, Anna. 1986. Comparative superlatives. MITWPL 8, 245-66. 